\title{
The Mutagenicity and Antimutagenicity of Canarium odontophyllum (Dabai) Acetone Leaves Extracts
}

\author{
Ahmad Rohi Ghazali ${ }^{1}$, Farah Mardhiah Khairuddin ${ }^{1}$, Tava Shelan Nagapan ${ }^{1} \&$ Dayang Fredalina Basri ${ }^{1}$ \\ ${ }^{1}$ Biomedical Science Programme, School of Diagnostic and Applied Health Sciences, Faculty of Health \\ Sciences, Universiti Kebangsaan Malaysia, Kuala Lumpur, Malaysia \\ Correspondence: Ahmad Rohi Ghazali, Biomedical Science Programme, School of Diagnostic and Applied \\ Health Sciences, Faculty of Health Sciences, Universiti Kebangsaan Malaysia, Jalan Raja Muda Abdul Aziz, \\ Kuala Lumpur 50300, Malaysia. Tel: 60-19-226-8976. E-mail: rohi@ukm.edu.my
}

Received: October 3, 2017

doi:10.5539/jas.v9n13p62
Accepted: December 10, 2017 Online Published: December 31, 2017

URL: https://doi.org/10.5539/jas.v9n13p62

\begin{abstract}
Canarium odontophyllum or locally known as Dabai in Sarawak is a fruit largely consumed by the locals. Based on previous studies, the plant possessed various biological activities, such as antimicrobial, antioxidant, antifungal and anticancer. Our aim was to investigate the mutagenicity and antimutagenicity of $C$. odontophyllum acetone leaves extracts by using the Ames test (Salmonella reverse mutagenicity assay).The Ames test also involved the pre-incubation method against Salmonella typhimurium TA98 and TA100 bacterial strains in the absence and presence of metabolic activator S9 system. C. odontophyllum crude acetone extracts were diluted with $10 \%$ DMSO to obtain three different concentrations of $3.125,12.5$ and $50 \mathrm{mg} / \mathrm{ml}$. To determine the mutagenicity effects of the extracts, each concentration of the extract was evaluated based on the two-fold value of the number of revertant's colony in negative control plate as the cut-of point. No mutagenic activity was observed for the frameshift mutation (TA98) and base-pair substitution mutation (TA100) in all concentrations of $C$. odontophyllum in the presence and absence of metabolic activator S9 system. Antimutagenicity test was carried out to determine the potential of $C$. odontophyllum extracts to inhibit the mutation induced by specific mutagens. The highest antimutagenic activity was seen in the presence of metabolic activator S9 system with inhibition percentage greater than $50 \%$ in both bacteria strains TA98 (62.38\%) and TA100 (58.24\%). In conclusion, C. odontophyllum acetone leaves extract was not mutagenic and had significant inhibitory effects on mutagenicity in both bacterial strains with and without the metabolic activator S9 system. Our results could contribute to the safe use of $C$. odontophyllum. In addition, based on the significant antimutagenic activity demonstrated by the $C$. odontophyllum acetone leaves extracts, the extract could also be developed as a chemopreventive agent.
\end{abstract}

Keywords: Canarium odontophyllum, dabai, mutagenic, antimutagenic

\section{Introduction}

Natural products are rich source of biological active compounds. Many medicines are either obtained directly from a natural source or were developed from a lead compound originally obtained from a natural source. They have been used as traditional medicine since ancient time by the old generations. Natural products can also be obtained from five different sources such as the plant kingdom, microorganisms, animal sources, marine, venom and toxin. However, among those five sources, plant is the main source of drug development. It is estimated that approximately $80 \%$ of the world population use plant extracts as traditional medicine for their primary health care needs (Craig, 1999). It was stated that about $25 \%$ of the drugs prescribed worldwide would come from plants and $11 \%$ from 252 drugs considered as basic and essential by the World Health Organization (WHO) are mainly originated from plant sources (Rates, 2001).

Nowadays people are turning into the use of natural sources as an alternative for treatment of diseases. One of the potential natural sources is C. odontophyllum. Locally it is known as dabai in Sarawak, and also called as 'Sibu Olive' by the local population in Sibu, Sarawak due to its physical appearance is similar to the olive fruit (Ding \& Tee, 2011). It can be found abundant in East Malaysia (Sabah and Sarawak) especially in Sibu, Kanowit and Kapit (Azlan et al., 2009). The plant can also be found in Indonesia (Kalimantan and Sumatera) as well as in Palawan, the Philippines. 
There are several previous scientific and pharmacological studies that have been done involving different parts of the plant which includes the leaves, fruits, pulp, seeds and stem bark. It has been reported that the leaves extracts of $C$. odontophyllum exhibited many medicinal properties such as anti-microbial activity (Basri et al. 2014), high antioxidant capacity (Basri et al., 2014) as well as hypoglycemic effect in diabetic induced rats (Saari et al., 2015). Besides, the fruit was also found to be a very good source for high energy, protein and fat, as well as minerals such as calcium, magnesium and phosphorus (Azlan et al., 2009). In addition, it was reported that the peel, pulp and kernel of C. odontophyllum also showed high antioxidant content (Prasad et al., 2011) as well as antifungal effects against Candida glabrata (Basri et al., 2014). Dabai seed had high anticholinesterase activity (Hassan, 2014). At the same time, the methanol and acetone extract of the stem bark could also cause cytotoxicity against human colorectal cancer HCT 116 (Basri et al., 2014). Hence, the plant has a great potential to be developed as a medicinal agent.

Previous studies also reported that $C$. odontophyllum possessed many therapeutic uses. However, there was no report regarding the mutagenicity and antimutagenicity of the plant extract. In order to develop the plants extracts into a drug, it is important to assess the safety of a compound. One of the basic safety screening test is the screening for mutagenicity by using the Ames test.

Ames test is a biological assay used to test the potential of a chemical/physical agent to cause permanent genetic alterations to an organism. It is an important procedure in the safety assessment of many new drugs. Besides, the study of antimutagenicity of the plant extracts may also be one of the key developments of a chemopreventive agent.

\section{Materials and Method}

\subsection{Plant Material}

Leaves of $C$. odontophyllum Miq. was obtained from Sarawak, Malaysia. All plant parts were identified and authenticated by Mr. Sani Miran and deposited in the Herbarium of the Universiti Kebangsaan Malaysia (UKM), Bangi, Selangor, Malaysia with a voucher specimen number of UKMB 40052. All chemicals were purchased from Sigma (USA) unless stated otherwise.

\subsection{Extraction Method}

The extraction was done in 1:5 ratio of sample to solvents where $100 \mathrm{~g}$ of dried leaves powder of $C$. odontophyllum was soaked in $500 \mathrm{ml}$ of acetone in a $1 \mathrm{~L}$ conical flask. Then, the mixture was shaken using orbital shaker for 24 hours at $100 \mathrm{rpm}$. After 24 hours, the mixture was then filtered by using Whatman No. 1 filter paper to collect the filtrate obtained. The residue of the leaves was soaked again for the second time in 300 $\mathrm{ml}$ of acetone and was left for 24 hours on orbital shaker at $100 \mathrm{rpm}$. The mixture was then filtered again through Whatman No. 1 filter paper to collect the filtrate. The first and second filtrate were combined together and concentrated under reduced pressure using rotary evaporator until it formed a pallet. Then the pallet obtained was left air-dried under fume hood to remove the remaining solvents in order to get a pure crude extracts. The final crude extracts were weighed to determine the percentage of yield and kept at $4^{\circ} \mathrm{C}$ until further used. The remaining residue from the acetone extraction was air-dried and weighed prior to the extraction of a new solvent.The percentage of yield extract for each solvent was calculated using the following formula (Basri et al., 2014):

$$
\text { Percentage of yield }(\%)=\frac{\text { Weight of crude extracts }(\mathrm{g})}{\text { Weight of dried leaves powder }(\mathrm{g})} \times 100 \%
$$

\subsection{Phytochemical Screening}

Phytochemical screening was carried out for alkaloids, tannins, saponins, flavonoids, phenolic compounds and terpenoids (Basri et al., 2014).

\subsection{Preparation of Sample}

In order to prepare a stock extract solution of $100 \mathrm{mg} / \mathrm{ml}, 100 \mathrm{mg}$ of acetone extract were dissolved with $1 \mathrm{ml}$ of $100 \%$ dimethyl sulfoxide (DMSO). Then, $9 \mathrm{ml}$ of sterile distilled water was added to the stock solution to dilute the DMSO solution to $10 \%$ concentration. The solution was mixed well with an autovortex until the solution was completely dissolved. The extract was sterilized by passing through a $0.22 \mu \mathrm{m}$ membrane filter. Then, the sample had undergone a serial dilution using $10 \%$ DMSO solution to a final concentration of $50 \mathrm{mg} / \mathrm{ml}, 12.5 \mathrm{mg} / \mathrm{ml}$ and $3.125 \mathrm{mg} / \mathrm{ml}$. The sample was stored in bijou bottle at $4{ }^{\circ} \mathrm{C}$ refrigerator until further use. 


\subsection{Bacterial Strains}

Salmonella typhimurium TA98 and TA100 strains were used in the mutagenicity and antimutagenicity (Ames) test. Both strains were mutant histidine dependent bacteria. Genetic analysis was performed for each tester strains to check their genotype charactersitics. Five genetic analysis tests need to be done on each tester strain were biotin dependence, histidine dependence, presence of $r f a$ mutation, presence of $u v r B$ mutation and presence of plasmid pKM101 (Mortelmans \& Zieger, 2000).

\subsection{Mutagens}

2-Nitrofluorene (2-NF), sodium azide $\left(\mathrm{NaN}_{3}\right)$ and 2-aminoanthracene (2-AA) were purchased from Sigma-Aldrich and dissolved in dimethyl-sulfoxide (DMSO).

\subsection{Mutagenicity Testing}

The method used to perform the mutagenicity test (Ames test) involved the pre-incubation method as described by Maron and Ames (1983). About $500 \mu \mathrm{l}$ of S9 mix (for the test with metabolic activation system) or phosphate buffer (for the test without metabolic activation system) was added into a sterile test tube followed by $100 \mu \mathrm{l}$ of acetone leaves extracts for each concentrations and finally $100 \mu \mathrm{l}$ of overnight grown bacterial culture. Then, the mixture was pre-incubated in reciprocal shaker waterbath at $37^{\circ} \mathrm{C}$ for 20 minutes. After 20 minutes, $2 \mathrm{ml}$ of top agar supplemented with histidine/biotine $(0.5 \mathrm{mM})$ was added into test tube. The mixture was gently mixed and poured onto the glucose minimal agar plate. After the agar had been solidified, all the agar plate was incubated invertedly at $37{ }^{\circ} \mathrm{C}$ for 48 hours and the number of revertant colonies growth per plate was counted and compared with the negative control plate.

\subsection{Antimutagenicity Testing}

In antimutagenicity test of acetone leaves extracts of $C$. odontophyllum, $500 \mu 1$ of S9 mix (for the test with metabolic activation system) or phosphate buffer (for the test without metabolic activation system) was added into a sterile test tube followed by $100 \mu \mathrm{l}$ of acetone leaves extracts for each concentrations, $100 \mu \mathrm{l}$ of positive control solution and finally $100 \mu \mathrm{l}$ of overnight grown bacterial culture. Then, the mixture was pre-incubated in reciprocal shaker waterbath at $37^{\circ} \mathrm{C}$ for 20 minutes. After 20 minutes, $2 \mathrm{ml}$ of top agar supplemented with histidine/biotine $(0.5 \mathrm{mM})$ was added into test tube. The mixture was gently mixed and poured onto the glucose minimal agar plate. After the agar has been solidified, all the agar plate was incubated invertedly at $37{ }^{\circ} \mathrm{C}$ for 48 hours and the number of revertant colonies growth per plate was counted and compared with the positive control plate. The results for antimutagenicity test were reported in mutagenicity inhibition percentage (MIP). It was calculated by using the equation as follows:

$$
\text { MIP }(\%)=(1-\mathrm{T} / \mathrm{M}) \times 100 \%
$$

Where, $\mathrm{T}$, as the number of revertants colonies per plate in the presence of mutagen and plant extract and $\mathrm{M}$ as the number of revertants per plate in the presence of mutagen only without the plant extracts. The data obtained was classified into three groups which were $0-25 \%$, no antimutagenic effect; $25-40 \%$, a moderate antimutagenic effect; value greater than $40 \%$ showed a strong antimutagenic effect (Negi et al., 2003).

\subsection{Statistical Analysis}

All data were expressed as mean \pm standard error mean (SEM). Statistical analysis was performed using Statistical Package for Social Science (SPSS) version 22 by employing one-way ANOVA. The data were considered statistically significant when $\mathrm{p}<0.05$.

\section{Results}

\subsection{Percentage Yield of the Plant Extracts}

Results of the percentage yield of the $C$. odontophyllum leaf crude extract from the sequential extraction of hexane, acetone and methanol were presented in Table 1. Based on Table 1, methanol was found to produce the highest percentage yield of $7.48 \%$ while hexane extract showed the lowest percentage of extraction yield which was $4.32 \%$. Acetone appeared to produce the second highest extraction yield of $5.01 \%$ from the dried powdered leaves. 
Table 1. The percentage of yield in three different solvents in the extraction of $C$. odontophyllum leaves

\begin{tabular}{llll}
\hline Extraction solvent & Weight of powdered sample $(\mathrm{g})$ & Weight of dry crude extract $(\mathrm{g})$ & Percentage yield (\%) \\
\hline Hexane & 100.000 & 4.323 & 4.323 \\
Acetone & 91.200 & 4.583 & 5.025 \\
Methanol & 85.227 & 6.417 & 7.477 \\
\hline
\end{tabular}

\subsection{Phytochemical Screening}

Table 2 showed the phytochemical screening of the C. odontophyllum acetone leaves extracts. Based on Table 2, the screening test clearly demonstrated that alkaloid, tannin, terpenoid and phenol were detected in the acetone leaves extracts. On the other hand, saponin and flavonoid however were absent in the acetone leaves extracts of C. odontophyllum. The amount of active compound presence in the acetone leaves extracts was evaluated based on the colour intensity resulted from the particular phytochemical test.

Table 2. Results of phytochemical contents of $C$. odontophyllum acetone leaves extracts

\begin{tabular}{ll}
\hline Phytochemical test & Acetone extract \\
\hline Alkaloid & ++ \\
Tannin & ++ \\
Saponin & - \\
Flavonoid & - \\
Phenol & + \\
Terpenoid & + \\
\hline
\end{tabular}

Note. (-): Absence of active compound; (+): Lower presence of active compound; (++): High presence of active compound.

\subsection{Mutagenicity Studies}

Figures 1(a) and 1(b) showed the mean number of bacterial revertant colonies of S. typhimurium strain TA98 and TA100 for the mutagenicity tests of $C$. odontophyllum acetone leaves extracts without metabolic activation system at three different concentrations compared to negative control. Based on the results, it showed that none of the concentrations induced two fold increase in the mean number of revertants relative to the negative control group in both bacteria strains TA98 and TA100.

Besides, our study also indicated that there was a significant different $(\mathrm{p}<0.01)$ in the number of revertant colonies of the S. typhimurium strains TA98 for all of the tested doses of $C$. odontophyllum acetone leaves extracts compared to the negative controls. Whereas bacteria strain TA100 showed high significant different value $(\mathrm{P}<0.001)$ in all three concentrations compared to the negative controls. 
(a)
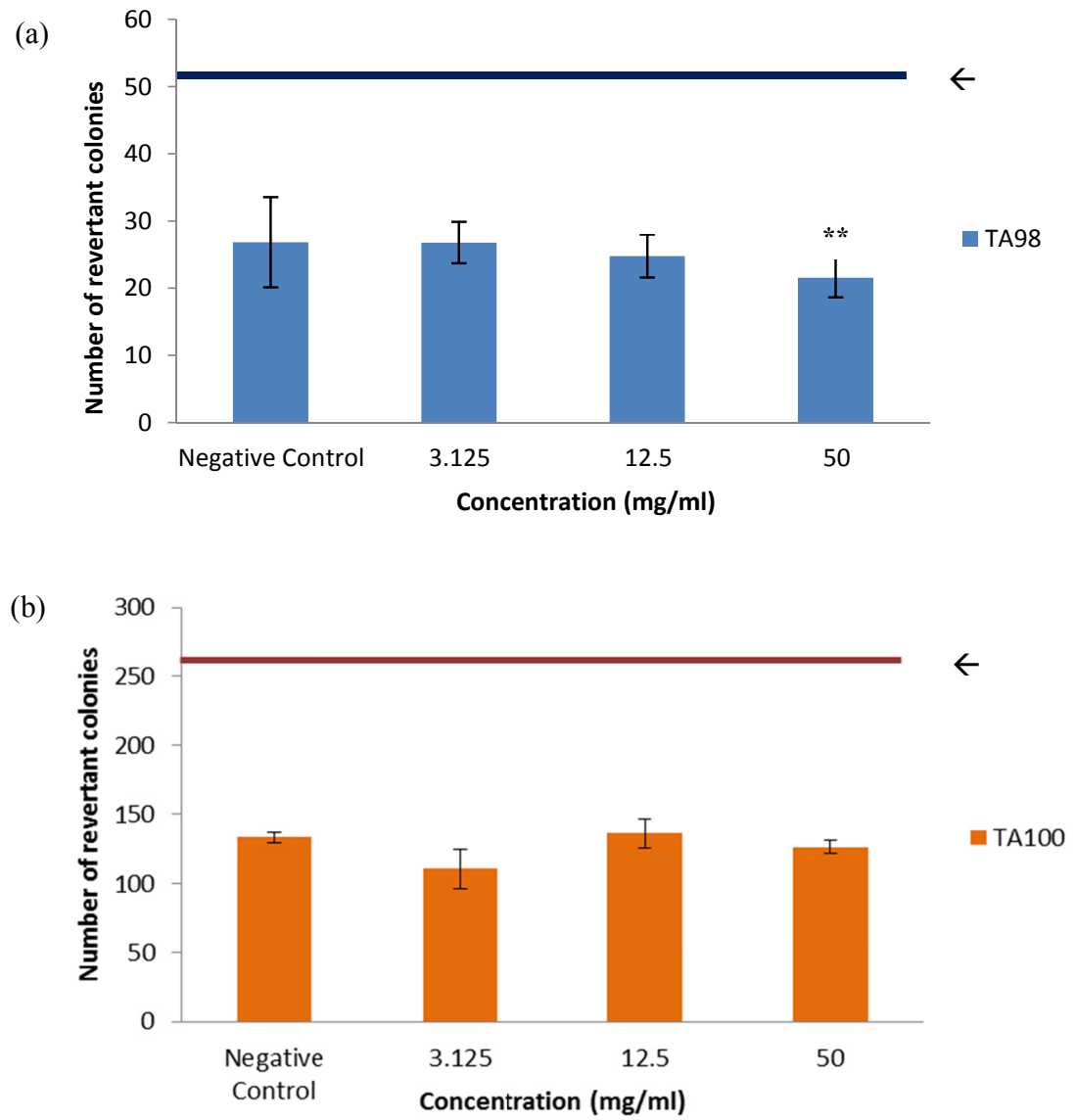

Figure 1. (a) The mean number of bacterial revertant colonies of Salmonella typhimurium strain TA98 for mutagenicity tests of $C$. odontophyllum acetone leaves extracts without metabolic activation system compared to negative control $(\mathrm{n}=3)$; (b) The mean number of bacterial revertant colonies of Salmonella typhimurium strain TA100 for mutagenicity tests of $C$. odontophyllum acetone leaves extracts without metabolic activation system compared to negative control $(\mathrm{n}=3)$

Note. ${ }^{* *}$ : Significance compare to negative control $(\mathrm{p}<0.01) ; * * *$ : Significance compare to negative control $(\mathrm{p}$ $<0.001) ; \leftarrow$ : Twice of the mean number of bacterial revertant colonies on negative control plate.

Figures 2(a) and 2(b) showed the mean number of bacterial revertant colonies of S. typhimurium strain TA98 and TA100 for mutagenicity tests of $C$. odontophyllum acetone leaves extracts with metabolic activation system at three different concentrations compared to negative control. Based on the results, it showed that none of the concentrations produced twice the mean number of revertants relative to the negative control group in both bacteria strains TA98 and TA100.

Our study also indicated that there was significant different $(\mathrm{p}<0.001)$ in the number of revertant colonies of the S. typhimurium strains TA100 at all tested doses of $C$. odontophyllum acetone leaves extracts compared to the negative controls. Whereas bacteria strain TA98 showed significant different $(\mathrm{P}<0.05)$ only at two concentrations $(12.5 \mathrm{mg} / \mathrm{ml}$ and $50 \mathrm{mg} / \mathrm{ml})$ and the lowest concentration of $3.125 \mathrm{mg} / \mathrm{ml}$ also showed significant different $(\mathrm{P}<0.01)$ compared to the negative controls group. 
(a)

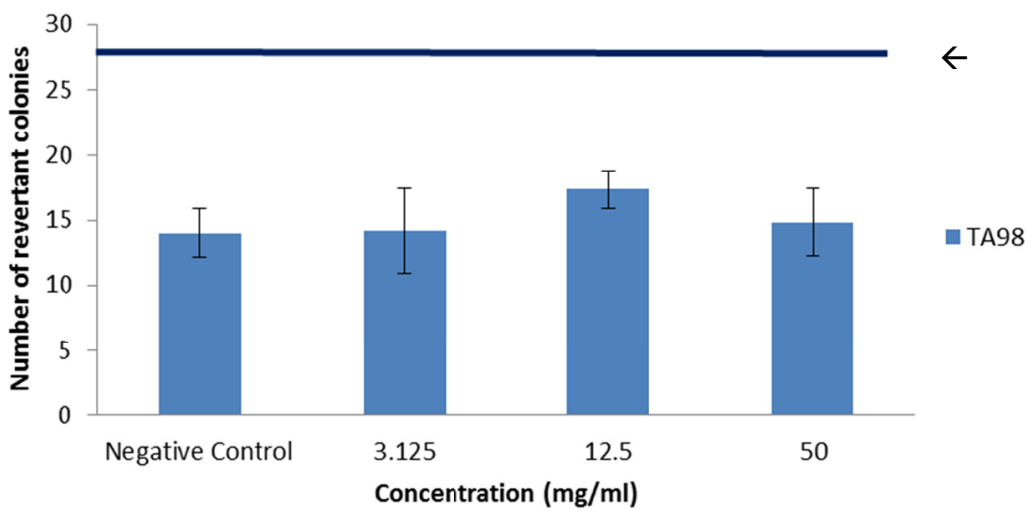

(b)

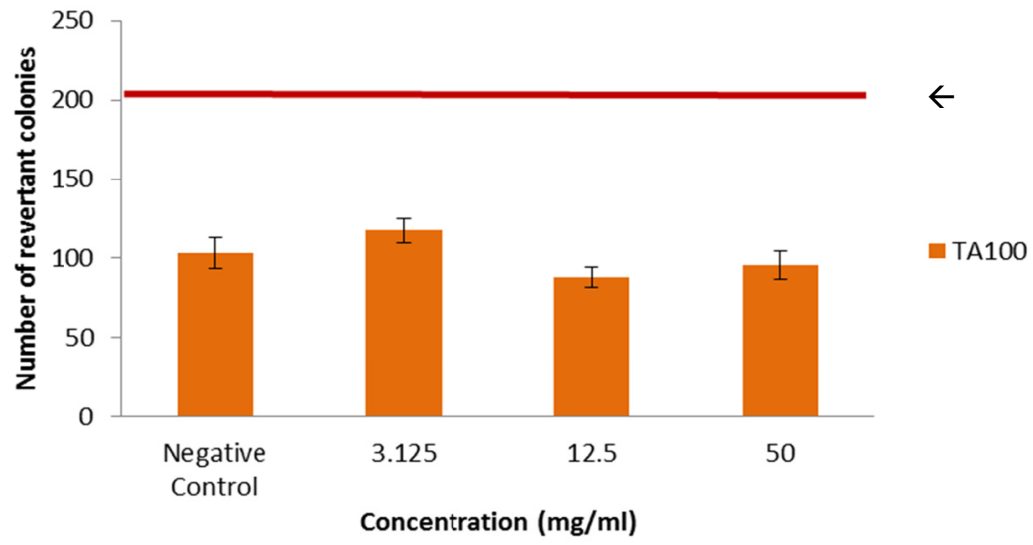

Figure 2. (a) The mean number of bacterial revertant colonies of Salmonella typhimurium strain TA98 for mutagenicity tests of $C$. odontophyllum acetone leaves extracts with metabolic activation system compared to negative control $(\mathrm{n}=3)$; (b) The mean number of bacterial revertant colonies of Salmonella typhimurium strain

TA100 for mutagenicity tests of $C$. odontophyllum acetone leaves extracts with metabolic activation system compared to negative control $(\mathrm{n}=3)$

Note. *: Significance compare to negative control $(\mathrm{p}<0.05) ; *$ : Significance compare to negative control $(\mathrm{p}<$ $0.01)$; ***: Significance compare to negative control $(\mathrm{p}<0.001) ; \leftarrow$ : Twice of the mean number of bacterial revertant colonies on negative control plate.

\subsection{Antimutagenicity Studies}

Figures 3(a) and 3(b) demonstrated the mean number of bacterial revertant colonies of S. typhimurium strain TA98 and TA100 for the antimutagenicity tests of $C$. odontophyllum acetone leaves extracts without metabolic activation system at three different concentrations compared to the positive control. One-way analysis of variance (ANOVA) test showed a significant difference between the treatment dose $50 \mathrm{mg} / \mathrm{ml}(\mathrm{p}<0.001)$ and $12.5 \mathrm{mg} / \mathrm{ml}(\mathrm{P}<0.05)$ with the positive control for bacteria strain TA98. On the other hand, there was significant differed in the number of revertant colonies of the $S$. typhimurium strains TA100 in all tested doses of $C$. odontophyllum acetone leaves extracts compared to the positive control $(\mathrm{p}<0.001)$.

The highest Mutagenicity Inhibitory (MIP) value of 2-nitrofluorene and sodium azide were $41.52 \%$ for bacteria strain TA98 and 48.52\% for bacteria strain TA100 respectively, Both (at concentration of $50 \mathrm{mg} / \mathrm{ml}$ ) showed strong antimutagenic activities. On the other hand, at the concentration of $3.125 \mathrm{mg} / \mathrm{ml}$ the plant leaves extracts did not exhibit any antimutagenic activity towards 2-nitrofluorene as it has showed the lowest MIP value which was $20.58 \%$ whereas at concentration of $12.5 \mathrm{mg} / \mathrm{ml}$ the MIP value reported was $25.63 \%$ indicating a moderate antimutagenic activity for strain TA98. Meanwhile, for bacteria strain TA100 the acetone leaves extracts showed a moderate antimutagenic activity with MIP value of $39.49 \%$ at concentration of $3.125 \mathrm{mg} / \mathrm{ml}$ and strong antimutagenic activity with MIP value of $43.17 \%$ at concentration of $12.5 \mathrm{mg} / \mathrm{ml}$. 
(a)
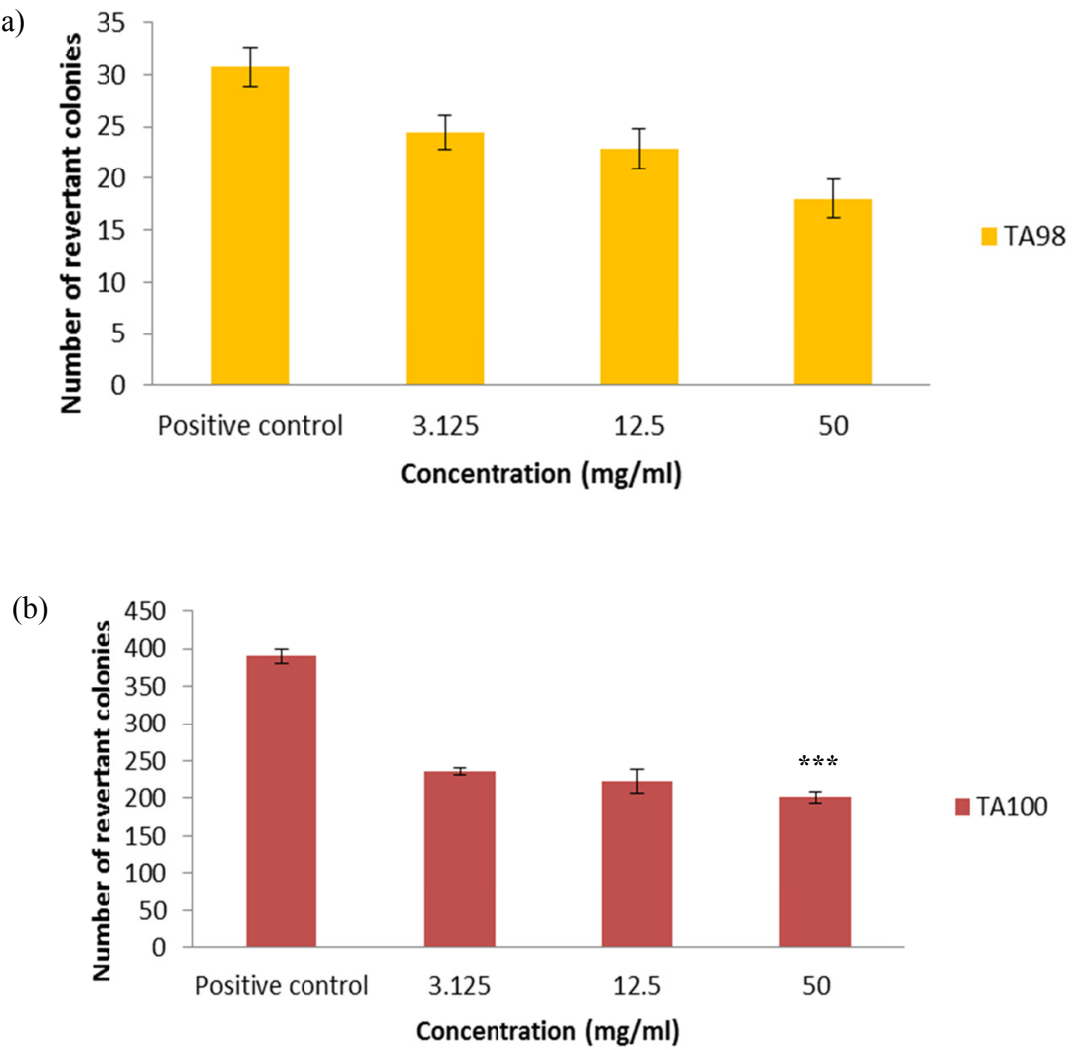

Figure 3. (a) The mean number of bacterial revertant colonies of Salmonella typhimurium strain TA98 for antimutagenicity tests of $C$. odontophyllum acetone leaves extracts without metabolic activation system compared to positive control $(\mathrm{n}=3)$; (b) The mean number of bacterial revertant colonies of Salmonella typhimurium strain TA100 for mutagenicity tests of $C$. odontophyllum acetone leaves extracts without metabolic activation system compared to positive control $(n=3)$

Note. *: Significance compare to positive control $(\mathrm{p}<0.05)$; ***: Significance compare to positive control $(\mathrm{p}<$ $0.001)$.

Figures 4(a) and 4(b) demonstrated the mean number of bacterial revertant colonies of S. typhimurium strain TA98 and TA100 for the antimutagenicity tests of $C$. odontophyllum acetone leaves extracts with metabolic activation system at three different concentrations compared to the positive control. One-way analysis of variance (ANOVA) test showed a significant inhibition of revertant colonies but only at two concentrations of 50 $\mathrm{mg} / \mathrm{ml}(\mathrm{p}<0.001)$ and $3.125 \mathrm{mg} / \mathrm{ml}(\mathrm{P}<0.05)$ for the bacteria strain TA98. On the other hand, there was significant different $(\mathrm{p}<0.001)$ at the number of revertant colonies of the S. typhimurium strains TA100 in two tested doses of $12.5 \mathrm{mg} / \mathrm{ml}$ and $50 \mathrm{mg} / \mathrm{ml}$ as well as concentration of $3.125 \mathrm{mg} / \mathrm{ml}(\mathrm{P}<0.05)$ of $C$. odontophyllum acetone leaves extracts compared to the positive control.

The highest MIP value of 2-aminoanthracene were $62.38 \%$ for the bacteria strain TA98 and $58.24 \%$ for bacteria strain TA100 both at concentration of $50 \mathrm{mg} / \mathrm{ml}$ where both showed strong antimutagenic activities. At the concentration of $12.5 \mathrm{mg} / \mathrm{ml}$ the acetone leaves extracts of $C$. odontophyllum did not exhibit any antimutagenic activity towards 2-aminoanthracene as it showed the lowest MIP value which was $21.22 \%$ whereas at concentration of $3.125 \mathrm{mg} / \mathrm{ml}$ the MIP value reported was $34.73 \%$ indicated a moderate antimutagenic activity for strain TA98. Meanwhile, for bacteria strain TA100 the acetone leaves extracts showed a moderate antimutagenic activity with MIP value of $26.44 \%$ at concentration of $3.125 \mathrm{mg} / \mathrm{ml}$ and $32.04 \%$ at concentration of $12.5 \mathrm{mg} / \mathrm{ml}$. 
(a)

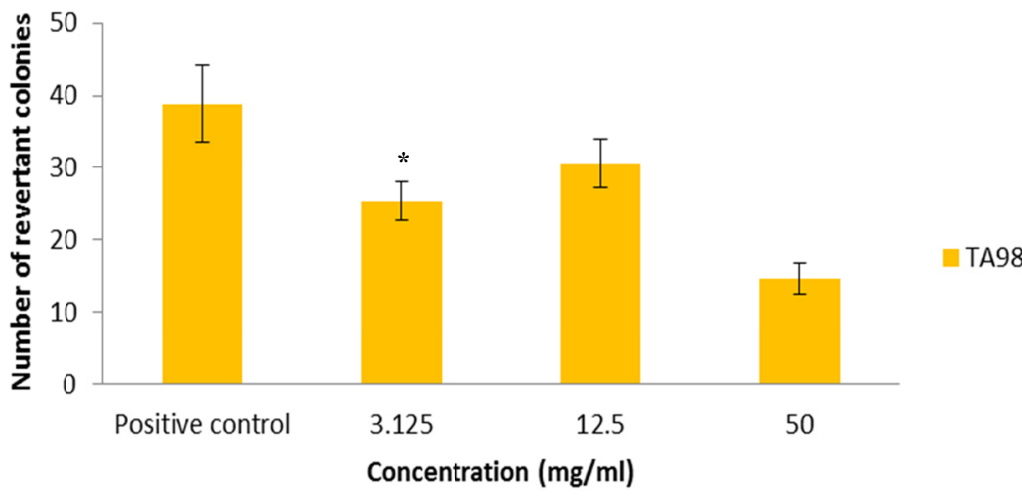

(b)

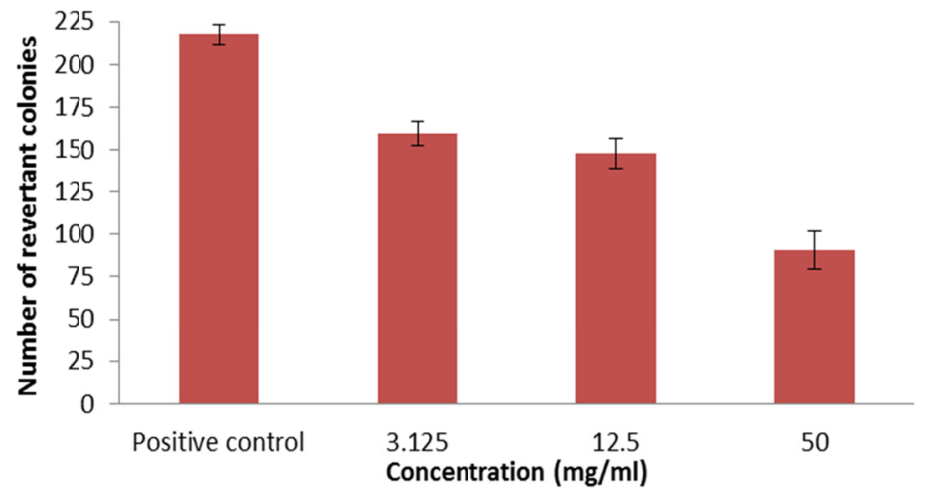

- TA100

Figure 4. (a) The mean number of bacterial revertant colonies of Salmonella typhimurium strain TA98 for antimutagenicity tests of $C$. odontophyllum acetone leaves extracts with metabolic activation system compared to positive control $(\mathrm{n}=3)$; (b) The mean number of bacterial revertant colonies of Salmonella typhimurium strain TA100 for antimutagenicity tests of $C$. odontophyllum acetone leaves extracts with metabolic activation system compared to positive control $(\mathrm{n}=3)$

Note. *: Significance compare to positive control $(\mathrm{p}<0.05)$; **: Significance compare to positive control $(\mathrm{p}<$ $0.001)$.

\section{Discussion}

In our study, the extraction of the C. odontophyllum leaves was done through sequential extraction method. The extraction method started with hexane which was the lowest polar solvent, followed by the acetone which was a semi polar and lastly methanol which had the highest polarity. Out of the three extracts, methanol extracts resulted in the highest percentage of yield with $7.447 \%$ followed by acetone with $5.025 \%$ and hexane with $4.323 \%$. High polarity of methanol produced the highest yield of extracts compared to the other solvents. Our results were consistent with the previous study done by Basri and Nor (2014) where the highest yield was also obtained from the most polar solvent.

Analysis of phytochemical screening of the acetone extract of $C$. odontophyllum leaves revealed the presence of all phytochemical compounds tested except for saponin and flavonoid. High amount of alkaloid and concentrated tannin were also observed from the test. Acetone organic solvents were reported to extract more tannin and phenolic compounds compared to methanol (Tiwari et al., 2011). However, in the previous study on the leaves extracts, more bioactive constituents had been detected which included saponin and flavonoid which were absent in this study (Basri \& Nor, 2014).

The maturity of the plant part might affect the quantity of an extract and its secondary metabolite composition resulting in variation of the phytochemicals extracted. Antioxidant study from Thi and Hwang (2014) of the aronia leaves showed that immature aronia leaves were more potent to have antioxidative ingredients due to its high content of polyphenols. 
It was reported that $C$. odontophyllum and its extract had moderate to strong antimutagenic activities. With the treatment of $C$. odontophyllum, the inhibition rates against 2-nitrofluorene ranged from 20.58 to $41.52 \%$ for strain TA98 and from 39.49 to $48.52 \%$ for strain TA100. While in other test with metabolic activation system $C$. odontophyllum leaves extracts showed antimutagenic activity at rates ranging from 21.22 to $62.38 \%$ for TA98 and 26.44 to $58.24 \%$ for the TA100.

The highest antimutagenic activity can be seen in the presence of S9 metabolic activation system with inhibition percentage greater than $50 \%$. Based on previous studies, it was reported that the mutagenicity inhibition rate was found to be effective in the presence of metabolic activation system (Horn \& Vargas, 2003). Metabolic activation system was prepared from $9000 \mathrm{~g}$ supernatant fraction of rat livers homogenate induced with Aroclor 1254 enzyme (OECD, 1997). The mutagenicity of S9 mutagen, 2-aminoanthracene was suppressed by acetone extracts of $C$. odontophyllum leaves by inactivation of the 2-aminoanthracene catalysed by the cytochrome $\mathrm{P} 450$ system thus prevented the occurrence of point mutation.

Besides, antimutagenic activity was also claimed mainly due to the tannin content which was a phenolic compound that could affect the mutagenic activities (Kada et al., 1985; Tanaka et al., 1998). Previous study done by (Imanishi et al., 1991) had reported that in the presence of metabolic activation system S9, tannin showed effective antimutagenic activity at low concentration thus enhance the activity of DNA excision repair by activating the repair enzyme (Shimoi et al., 1985).

The study in concordance with the observation of significant antimutagenic activity of two plants Maytenus ilicifolia and Peltastes peltatus, both contained flavonoid and tannin. They reported presence of flavonoids and tannins or their derivatives in the samples were previously described as possessing antimutagenic properties by interfering the mutagen activation (Horn \& Vargas, 2003). Therefore, high content of tannin from the acetone leaves extract of $C$. odontophyllum could possibly responsible for its significant antimutagenic effect towards the mutagen used in the Ames test.

Investigation of antimutagenic activity of plant extracts is essential in the discovery of new chemopreventive agent. Non-mutagenic and significant antimutagenic activity showed by $C$. odontophyllum acetone leaves extracts provides a scientific validation for the traditional use of these plants. Our results contributed to valuable data on the safe use of $C$. odontophyllum and its potential chemopreventive effects.

\section{Conclusion}

In conclusion, $C$. odontophyllum acetone leaves extracts was not shown to be mutagenic and had inhibitory effects on the mutagen induced mutagenicity in the Ames test. C. odontophyllum acetone leaves extract was unable to induce frameshift mutation in Salmonella typhimurium bacteria strain TA98 and base-pair substitution mutation in Salmonella typhimurium TA100 in the absence and presence of metabolic activation system. The extracts also exhibited significant antimutagenic effect as it can inhibit the mutagenic activity of 2-nitrofluorene, sodium azide and 2-aminoanthracene mutagen in both Salmonella typhimurium bacteria strains TA98 and TA100 in the presence and absence of metabolic activation system.

\section{References}

Azlan, A., Nasir, N. N. M., Amom, Z., \& Ismail, A. (2009). Physical properties of skin, flesh, and kernel of Canarium odontophyllum fruit. Journal Food Agriculture Environment, 7, 55-7.

Badami, S., Moorkoth, S., Rai, S. R., Kannan, E., \& Bhojraj, S. (2003). Antioxidant activity of Caesalpinia sappan heartwood. Biological \& Pharmaceutical Bulletin, 26(11), 1534-1537. https://doi.org/10.1248/ bpb.26.1534

Basri, D. F., \& Nor, N. H. M. (2014). Phytoconstituent Screening and Antibacterial Activity of the Leaf Extracts from Canarium odontophyllum Miq. American Journal of Plant Sciences, 5(Sept.), 2878-2888. https://doi.org/10.4236/ajps.2014.519303

Basri, D. F., Arifuddin, M., Rasyid, A., Meng, C. K., Latif, E. S., \& Huyop, F. Z. (2014). Cytotoxic Activity of Stem Bark Extracts from Canarium odontophyllum Miq. (Dabai) against Human Colorectal Carcinoma HCT 116 Cell Line. American Journal of Plant Sciences, 5(26), 3925-3933. https://doi.org/10.4236/ ajps.2014.526411

Basri, D. F., Heng, K. Y., Meng, C. K., \& Ghazali, A. R. (2014). Screening of antioxidant phytoextracts of Canarium odontophyllum Miq. leaves in vitro. IOSR Journal of Pharmacy, 4(12), 1-6. 
Basri, D. F., Saidi, N., Mahari, H., Saari, S., \& Santhanam, J. (2014). Preliminary screening for antimicrobial activity of the pulp of Canarium odontophyllum Miq. (Dabai) fruit. Global Journal of Pharmacology, 8(2), 213-220. https://doi.org/10.5829/idosi.gjp.2014.8.2.82415

Basri, D. F., Zainal, N. H., \& Santhanam, J. (2014). The potential of Canarium odontophyllum Miq. (dabai) as anti-methicillin resistant Staphylococcus aureus agent. International Journal of Pharmacy and Pharmaceutical Sciences, 6(9), 290-93.

Craig, W. J. (1999). Health-promoting properties of common herbs. The American Journal of Clinical Nutrition, 70(Suppl. 3), 491S-499S.

Ding, P., \& Tee, Y. K. (2011). Physicochemical characteristics of dabai (Canarium odontophyllum Miq.) fruit. Fruits, 66(1), 47-52. https://doi.org/10.1051/fruits/2010040

Hassan, A. S. H., Fry, J. R., \& Abu-Bakar, M. F. (2014). Antioxidative phytochemicals and anti-cholinesterase activity of native kembayau (Canarium odontophyllum) fruit of Sabah, Malaysian Borneo. Journal of Nutrition \& Food Sciences, 4(1), 1000249. https://doi.org/10.4172/2155-9600.1000249

Horn, R. C., \& Ferrão Vargas, V. M. (2003). Antimutagenic activity of extracts of natural substances in the Salmonella/microsome assay. Mutagenesis, 18(2), 113-118. https://doi.org/10.1093/mutage/18.2.113

Imanishi, H., Sasaki, Y. F., Ohta, T., Watanabe, M., Kato, T., \& Shirasu, Y. (1991). Tea tannin components modify the induction of sister-chromatid exchanges and chromosome aberrations in mutagen-treated cultured mammalian cells and mice. Mutation Research/Genetic Toxicology, 259, 79-87. https://doi.org/ 10.1016/0165-1218(91)90111-X

Kada, T., Kaneko, K., Matsuzaki, S., Matsuzaki, T., \& Hora, Y. (1985). Detection and chemical identification of natural bio-antimutagens. A case of the green tea factor. Mutation Research/Fundamental and Molecular Mechanisms of Mutagenesis, 150(1-2), 127-132. https://doi.org/10.1016/0027-5107(85)90109-5

Maron, D. M., \& Ames, B. N. (1983). Revised methods for the Salmonella mutagenicity test. Mutation Research/Environmental Mutagenesis and Related Subjects, 113(3-4), 173-215. https://doi.org/10.1016/ 0165-1161 (83)90010-9

Mortelmans, K., \& Zeiger, E. (2000). The Ames Salmonella/microsome mutagenicity assay. Mutation Research/Fundamental and Molecular Mechanisms of Mutagenesis, 455(1-2), 29-60. https://doi.org/ 10.1016/S0027-5107(00)00064-6

Negi, P., Jayaprakasha, G., \& Jena, B.S. (2003). Antioxidant and antimutagenic activities of pomegranate peel extracts. Food Chemistry, 80(3), 393-397. https://doi.org/10.1016/S0308-8146(02)00279-0

OECD. (1997). Bacterial reverse mutation test. OECD Guidelines for testing of chemicals (No. 471). Organisation for Economic Co-operation and Development Paris.

Patel V. R., Patel P. R., \& Kajal S. S. (2010). Antioxidant activity of some selected medicinal plants in Western region of India. Advances in Biological Research, 4(1), 23-26

Prasad, K. N., Chew, L. Y., Khoo, H. E., Yang, B., Azlan, A., \& Ismail, A. (2011). Carotenoids and antioxidant capacities from Canarium odontophyllum Miq. fruit. Food Chemistry, 124(4), 1549-1555. https://doi.org/ 10.1016/j.foodchem.2010.08.010

Rates, S. M. K. (2001). Plants as source of drugs. Toxicon, 39(5), 603-613. https://doi.org/10.1016/S0041-0101 (00)00154-9

Saari, S. M., Basri, D. F., Budin, S. B., \& Warif, N. M. A. (2015). Effects of Canarium odontophyllum leaves on plasma glucose and T lymphocyte population in streptozotocin-induced diabetic rats. Saudi Journal of Biological Sciences, 24(2), 320-323. https://doi.org/10.1016/j.sjbs.2015.09.032

Shimoi, K., Nakamura, Y., Tomita, I., \& Kada, T. (1985). Bio-antimutagenic effects of tannic acid on UV and chemically induced mutagenesis in Escherichia coli B/r. Mutation Research/Fundamental and Molecular Mechanisms of Mutagenesis, 149(1), 17-23. https://doi.org/10.1016/0027-5107(85)90004-1

Tanaka, K., Hayatsu, T., Negishi, T., \& Hayatsu, H. (1998). Inhibition of N-nitrosation of secondary amines in vitro by tea extracts and catechins. Mutation Research/Genetic Toxicology and Environmental Mutagenesis, 412(1), 91-98. https://doi.org/10.1016/S1383-5718(97)00178-2 
Thi, N. D., \& Hwang, E. S. (2014). Bioactive compound contents and antioxidant activity in Aronia (Aronia melanocarpa) leaves collected at different growth stages. Preventive Nutrition and Food Science, 19(3), 204. https://doi.org/10.3746/pnf.2014.19.3.204

Tiwari, P., Kumar, B., Mandeep, K., Kaur, G., \& Kaur, H. (2011). Phytochemical screening and Extraction: A Review. Internationale Pharmaceutica Sciencia, 1(1), 98-106.

\section{Appendix}

Appendix 1. Mutagenic activities of $C$. odontophyllum acetone leaves extracts without (-S9) and with (+S9) metabolic activation system

\begin{tabular}{llll}
\hline Strain & Concentration & Mean \pm SEM (-S9) & Mean \pm SEM (+S9) \\
\hline TA98 & Negative control & $26.83 \pm 7$ & $14 \pm 2$ \\
TA98 & $3.125 \mathrm{mg} / \mathrm{ml}$ & $26.78 \pm 3$ & $14.17 \pm 3$ \\
TA98 & $12.5 \mathrm{mg} / \mathrm{ml}$ & $24.78 \pm 3$ & $17.33 \pm 1$ \\
TA98 & $50 \mathrm{mg} / \mathrm{ml}$ & $21.56 \pm 3$ & $14.83 \pm 3$ \\
TA100 & Negative control & $133.17 \pm 3$ & $103.33 \pm 10$ \\
TA100 & $3.125 \mathrm{mg} / \mathrm{ml}$ & $110.5 \pm 14$ & $117.5 \pm 8$ \\
TA100 & $12.5 \mathrm{mg} / \mathrm{ml}$ & $136.17 \pm 10$ & $88.33 \pm 6$ \\
TA100 & $50 \mathrm{mg} / \mathrm{ml}$ & $126.5 \pm 5$ & $95.83 \pm 9$ \\
\hline
\end{tabular}

Note. Negative control $=10 \%$ DMSO.

Appendix 2. Antimutagenic Activities of C. odontophyllum Acetone Leaves Extracts Without (-S9) and With (+S9) Metabolic Activation System

\begin{tabular}{llllll}
\hline Strain & Concentration & Mean \pm SEM (-S9) & Inhibition rate (\%) & Mean \pm SEM (+S9) & Inhibition rate (\%) \\
\hline TA98 & Positive control & $30.78 \pm 2$ & N/A & $38.88 \pm 5$ & N/A \\
TA98 & $3.125 \mathrm{mg} / \mathrm{ml}$ & $24.44 \pm 2$ & 20.58 & $25.38 \pm 3$ & 34.73 \\
TA98 & $12.5 \mathrm{mg} / \mathrm{ml}$ & $22.89 \pm 2$ & 25.63 & $30.63 \pm 3$ & 21.22 \\
TA98 & $50 \mathrm{mg} / \mathrm{ml}$ & $18 \pm 2$ & 41.52 & $14.63 \pm 2$ & 62.38 \\
TA100 & Positive control & $390.22 \pm 9$ & N/A & $217.38 \pm 6$ & N/A \\
TA100 & $3.125 \mathrm{mg} / \mathrm{ml}$ & $236.11 \pm 5$ & 39.49 & $159.90 \pm 7$ & 26.44 \\
TA100 & $12.5 \mathrm{mg} / \mathrm{ml}$ & $221.78 \pm 16$ & 43.17 & $147.72 \pm 9$ & 32.04 \\
TA100 & $50 \mathrm{mg} / \mathrm{ml}$ & $200.89 \pm 7$ & 48.52 & $90.78 \pm 12$ & 58.24 \\
\hline
\end{tabular}

Note. Positive control; Strain TA98 (-S9 = 2-NF, +S9 = 2AA), Strain TA100 (-S9 = NaN $3,+\mathrm{S} 9=2 \mathrm{AA})$; N/A = Non-applicable.

\section{Copyrights}

Copyright for this article is retained by the author(s), with first publication rights granted to the journal.

This is an open-access article distributed under the terms and conditions of the Creative Commons Attribution license (http://creativecommons.org/licenses/by/4.0/). 